\title{
Structure-Based Virtual Screening for Differential Inhibition of Aldose Reductase, Implicated in Secondary Complications in Diabetes
}

\author{
Gurprit Sekhon and Ranvir Singh* \\ Department cum National Centre for Human Genome Studies \& Research, Panjab University, India
}

Submission: October 14, 2021; Published: October 29, 2021

*Corresponding author: Ranvir Singh Department cum National Centre for Human Genome Studies \& Research, Pharmacy Extention Block, Panjab University, Chandigarh 160014, India

\begin{abstract}
As a clinically relevant drug target, there have been several attempts to design a structure-based inhibitor for aldose reductase (AR). Since most of the aldehydes are presented to AR conjugated with glutathione, in present work, the structure of AR complexed with NADPH and a glutathione analog was used as a target for virtual screening of small molecule library. Due to interactions of the glutathione backbone with the binding pocket of AR, the ternary complex (AR@NADPHODCEG) represents a unique conformation of AR backbone. NCI diversity set V was used as a small molecules library for virtual screening. AutoDock Vina was used for docking and scoring of ligands. Few select hits with low binding free energy were obtained, which may be potential leads for a search of an differential inhibitor against AR.
\end{abstract}

Keywords: Aldose reductase; Diabetes; Oxidative stress; Differential inhibition; Virtual screening

\section{Introduction}

Structure-based virtual screening is an established tool to identify lead molecules in the drug discovery process [1-3]. Virtual screening is a practical approach to cut down the time and cost required for drug discovery [4-5]. Advances in biophysical methods have provided much-needed information for structurebased drug design [6].

AR has been a drug target for secondary diabetic complications for almost four decades [7]. Many inhibitors have been developed which were efficacious in animal models but failed in clinical trials. Reasons for failure of inhibitors in clinical trials have been mainly toxicity and lack of specificity resulting in cross-reactivity with other Aldo-keto reductases (AKRs) [8]. The structural detail and catalytic mechanism of AR have been extensively studied [910].

Structure-based virtual screening for AR has been performed based on the high-resolution crystal structure of AR complexed with inhibitors [11]. As AR shows pronounced induced fit upon binding inhibitors, a virtual screening study has been performed considering multiple binding pocket conformations of AR [12,13]. A virtual screening study combined with structure-based lead optimization has also been reportedfor AR [14].

Using another approach called 'in-situ cross-docking' to address the multiple conformations, a study has been performed to find the inhibitors against AR using similarity search [15]. Pharmacophore modeling from multiple inhibitors of AR andvirtual screening based on the model has also been done [16]. One of the primary reasons for the failure of ARI's in clinical trials has been toxicity, and an attempt has been made in photochemical based virtual screening by docking and molecular dynamics simulation [17]. After all these efforts, to date, no AR inhibitorbased therapy is available for diabetes except an inhibitor 'Eplerestat,' which is used as a drug in India and Japan for acute diabetic neuropathy [8].

The interactions of substrates or inhibitors with the active site of AR are primarily hydrophobic. The $\mathrm{C}$-terminal region from amino acid residues 298-302 has been shown to interact with the carboxylic group of alrestatin, an AR inhibitor [18]. Removal 


\section{Current Research in Diabetes \& Obesity Journal}

of C terminus tail in AR leads to loss of substrate specificity [19]. As amino acid residues Cys-298, Ala-299, Leu-301, and Ser-302 from C-terminal tail of AKRs are least conserved among family members, these residues have been proposed to be essential for substrate specificity and hence useful target to develop a specific inhibitor for AR [18].

The glutathione analog, DCEG [S-(1,2-dicarboxyethyl) glutathione], is a competitive inhibitor of AR with a Kivalue of $0.02 \mathrm{mM}$ [20]. In the crystal structure of AR with DCEG, it has been shown that due to interactions between DCEG and AR, the protein backbone adopts a unique conformation [21]. The present study reports the virtual screening hits obtained from docking of the smallmolecules from NCI diversity set library into the crystal structure of the ternary complex (AR@NADPHODCEG).

\section{Materials And Methods}

\section{Small molecules library}

A ligand library, 'NCI diversity-set V,'consisting of 1593 small molecules, was selected for virtualscreening. 'The diversity-set $V^{\prime}$ represents the diversity of more than 200,000 compounds submitted to the DTP (Developmental Therapeutics Program) repository at NCI (National Cancer Institute) for biological evaluation (https://wiki.nci.nih.gov/display/ncidtpdata/ compound+sets). The compounds can be obtained from DTP for non-clinical research purposes at no cost.

\section{Receptor and ligand preparation}

The receptor and ligands were protonated and assigned atomic charges by using scripts from AutoDockTools (http://autodock. scripps.edu/resources/adt). Information regarding protonation states, charge distribution, and flexibility of receptor was added to receptor and ligand files by converting them to the 'pdbqt' format, which is the default format recognized by AutoDock Vina [22].

\section{Docking}

AutoDock Vina was used to predict the binding mode and binding freeenergy $\left(\Delta \mathrm{G}_{\text {bind }}\right)$ between ligands and the receptor [22]. A two-step hierarchical approach was adopted for docking. In the first step, ligands were docked into the AR without considering the flexibility of the receptor, and grid dimensions were chosen to enclose the whole receptor molecule. Grid spacing was set to the default value of $0.375 \AA$ A. Pyryx was used to set up AutoDock Vina for molecular docking of ligands with a rigid receptor [23]. Four independent docking runs were performed with exhaustiveness value set to $4,8,10$, and 15 , respectively.

Figure 1: Grid box and flexible residues information for the binding pocket of AR. The cubic grid box is shown in black, AR is shown in grey cartoon representation, and amino acid residues with flexible side chains are shown in stick representation and labeled.

For the second step, top docking hits with a higher binding affinity $\left(\Delta \mathrm{G}_{\text {bind }} \leq-10 \mathrm{Kcal} \mathrm{mol}^{-1}\right)$ were selected from the first step. Flexible receptor-ligand docking was set up in the AutoDock/ Vina plugin for PyMOL (http://www3.mpibpc.mpg.de/). The side chains of Trp-20, Tyr-48, His-110, His-111, Phe-122, Trp-219, Cys-298, Leu-299, Leu-300, and Ser-302 were treated as flexible. The cubic grid box was set enclosing the active site residues with a side length of $30 \AA$, having 150 points with grid-spacing set to $0.2 \AA$ (Figure 1). For comparison of binding affinity, DCEG was also docked into the receptor with similar parameters.

\section{Results}

Two-step hierarchical screening for docking the chemical table into the active site of hAR was performed. To cut down the number of ligands for the next step, in the first step, docking without any assumption of the binding site (blind docking) was performed, and receptor flexibility was not taken into account. In the second step, the binding site was defined, and side chains of critical binding site residues were considered flexible. For the first step, four independent docking runs were performed with varying 


\section{Current Research in Diabetes \& Obesity Journal}

exhaustiveness. All the ligands with binding energy higher than the cut-off value $\left(\Delta \mathrm{G}_{\text {bind }}>-10 \mathrm{Kcal} \mathrm{mol}^{-1}\right)$ were discarded. Using this criterion of $-10 \mathrm{Kcal} \mathrm{mol}^{-1}$ as the cut-off value, four docking runs yielded 134, 126, 111 and 135 hits, respectively. As expected, most of the hits were the same from independent runs, and after combining all the hits, 155 molecules were obtained for flexible docking in step-2. The molecules obtained as hits from step-1,155 in total, satisfactorily docked in the binding pocket of AR, although no binding site information was provided for docking (Figure 2).

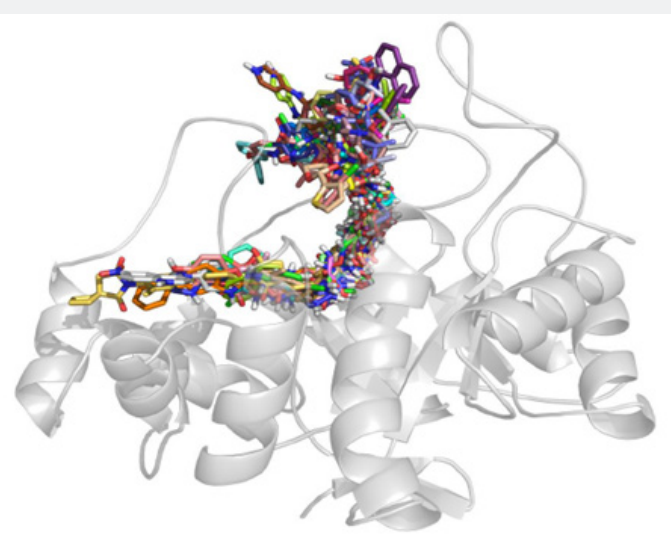

Figure 2: Molecules obtained from rigid docking with aldose reductase (AR). The best poses of 155 molecules shortlisted for step-2 docking are shown as stick representation. AR is shown in grey cartoon representation.

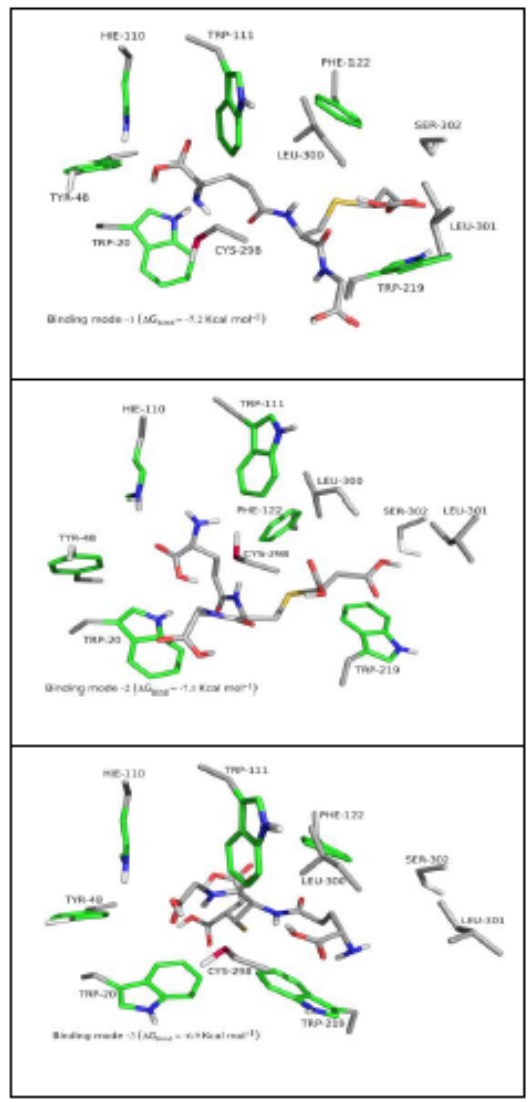

Figure 3: Docking of S-(1,2-dicarboxyethyl) glutathione, DCEG, with aldose reductase (AR). Three binding modes of DCEG into the binding pocket of AR are shown along with flexible side chains of amino acid residues. Both DCEG and amino acid residues are shown in stick representation, and amino acid residues are labeled. 


\section{Current Research in Diabetes \& Obesity Journal}

The 155 hits obtained from the first step were docked into the defined binding site of AR, and side chains of some critical binding site residues were treated as flexible. Top hits from flexible docking were selected based on binding free energy ( $\Delta$ Gbind $\leq$ -12 Kcal mol-1). A total of 28 molecules with higher binding affinity were obtained from the second docking step (Table 1). The binding modes of all the molecules obtained as hits from the second docking step are given in Appendix at the end of this chapter. The average binding free energy of DCEG was calculated to be $-7.1 \mathrm{Kcal} \mathrm{mol}^{-1}$ (Figure 3).

Table 1: Hits obtained from virtual screening of ' $\mathrm{NCl}$ diversity set $\mathrm{V}$ ' against aldose reductase ternary complex with NADPH and glutathione analog, DCEG, are listed along with corresponding binding free energy and NSC number.

\begin{tabular}{|c|c|c|}
\hline Serial Number & NSC Number & $\Delta \mathrm{G}_{\text {bind }}\left(\mathrm{Kcal} \mathrm{mol}^{-1}\right)$ \\
\hline 1 & 97920 & -14.10 \\
\hline 2 & 670283 & -13.00 \\
\hline 3 & 21970 & -12.90 \\
\hline 4 & 80313 & -12.90 \\
\hline 5 & 121868 & -12.60 \\
\hline 6 & 345647 & -12.60 \\
\hline 7 & 308835 & -12.30 \\
\hline 8 & 84100 & -12.30 \\
\hline 9 & 96021 & -12.30 \\
\hline 10 & 116702 & -12.20 \\
\hline 11 & 122819 & -12.20 \\
\hline 12 & 128606 & -12.20 \\
\hline 13 & 211490 & -12.20 \\
\hline 14 & 61610 & -12.20 \\
\hline 15 & 727038 & -12.20 \\
\hline 16 & 135168 & -12.10 \\
\hline 17 & 177862 & -12.10 \\
\hline 18 & 217697 & -12.10 \\
\hline 19 & 332670 & -12.10 \\
\hline 20 & 637827 & -12.10 \\
\hline 21 & 80731 & -12.10 \\
\hline
\end{tabular}

\section{Discussion}

Diabetes is one of the most significant health burdens in developed as well as developing countries [24-26]. The inhibition of AR has been perceived as one of the therapeutic solutions to control secondary diabetic complications for many decades [Yan_2018]. Although alot of potent inhibitors against AR have entered into the clinical trials, the success rate has been unsatisfactory [8]. In terms of in vitro inhibition, the ARI's had reached perfection long ago, with IC50 values in nanomolar (nm) range for many inhibitors. From thereon, the main problem has been their poor pharmacokinetics and cross-reactivity with other AKRs, especially aldehyde reductase [28]. Spirohydantoins class of ARI's were first to be reported effective both in vitro and in vivo, but hydantoin moiety caused hypersensitivity reactions [7].

Spirosuccinimides were derived from spirohydantoins, where the hydantoid ring was replaced with a succinimide ring [29]. Ranirestat is one such succinimide that is effective in motor nerve function in mild to moderate diabetic sensorimotor polyneuropathy (DSP) [30]. Poor pharmacokinetics has been the primary reason for the failure of the carboxylic acid class of ARI's, which otherwise showed the highest in vitro affinity. However, Epelrestat is an exception whichis a carboxylic acid inhibitor and is being successfully used for diabetic neuropathy in Japan. To obtain optimal pharmacokinetic properties, the structure-based optimization of lead compounds is relevant for further ARI's development [14,31,32].

The crystal structure of AR bound with glutathione analog, DCEG, represents a unique conformation of AR backbone, which is specific for interactions with glutathione backbone. NCI diversity set was screened against this conformation of AR, and a few lead molecules with low binding free energy have been obtained (Table 1). Most of these molecules obtained from the virtual screening are hydrophobic compounds with aromatic rings (Appendix). This 


\section{Current Research in Diabetes \& Obesity Journal}

work has led to a set of 28 small molecules that seem to have the potential to act as inhibitors for AR, which needs to be tested and validated experimentally. Present work has laid the foundation for discovery/design of novel inhibitors against AR.

\section{Acknowledgements}

Gurprit Sekhon acknowledgesResearch Fellowship from UGC, Govt. of INDIA.

\section{Funding Sources}

No funding sources were involved in this research work.

\section{Disclosure of Conflicts of Interest}

Authors declare that there was no conflict of interest.

\section{References}

1. Lounnas V, Ritschel, T, Kelder J, McGuire R, Bywater RP, et al. (2013) Current progress in Structure-Based Rational Drug Design marks a new mindset in drug discovery. Comput Struct Biotechnol J 5(6): e201302011.

2. Spyrakis F, Cavasotto CN (2015) Open challenges in structure-based virtual screening: Receptor modeling, target flexibility consideration and active site water molecules description. Archives of Biochemistry and Biophysics 583: 105-119.

3. Batool M, Ahmad B, Choi S (2019) A Structure-Based Drug Discovery Paradigm. Int J Mol Sci 20(11): 2783.

4. Smietana K, Siatkowski M, Møller M (2016) Trends in clinical success rates. Nature Reviews Drug Discovery 15(6): 379-380.

5. Mullard A (2019) 2018 FDA drug approvals. Nat Rev Drug Discov 18(2): 85-89.

6. Renaud JP, Chung CW, Danielson UH, Egner U, Hennig M, et al. (2016) Biophysics in drug discovery: impact, challenges and opportunities. Nature Reviews Drug Discovery 15(10): 679-698.

7. Maccari R, Ottanà R (2015) Targeting Aldose Reductase for the Treatment of Diabetes Complications and Inflammatory Diseases: New Insights and Future Directions. Journal of Medicinal Chemistry 58(5): 2047-2067.

8. Quattrini L, La Motta C (2019) Aldose reductase inhibitors: 2013-present. Expert Opinion on Therapeutic Patents 29(3): 199-213.

9. El Kabbani O, Ruiz F, Darmanin C, Chung RPT (2004) Aldose reductase structures: implications for mechanism and inhibition. Cellular and Molecular Life Sciences CMLS 61(7-8): 750-762.

10. Dréanic MP, Edge CM, Tuttle T (2017) New Insights into the Catalytic Mechanism of Aldose Reductase: A QM/MM Study. ACS Omega 2(9): 5737-5747.

11. Kraemer O, Hazemann I, Podjarny AD, Klebe G (2004) Virtual screening for inhibitors of human aldose reductase. Proteins: Structure, Function, and Bioinformatics 55(4): 814-823.

12. Sotriffer CA, Krämer O, Klebe G (2004) Probing flexibility and "inducedfit" phenomena in aldose reductase by comparative crystal structure analysis and molecular dynamics simulations. Proteins: Structure, Function, and Bioinformatics 56(1): 52-66.

13. Wang L, Gu Q Zheng X, Ye J, Liu Z, et al. (2013) Discovery of New Selective Human Aldose Reductase Inhibitors through Virtual Screening Multiple Binding Pocket Conformations. Journal of Chemical Information and Modeling 53(9): 2409-2422.
14. Eisenmann M, Steuber H, Zentgraf M, Altenkämper M, Ortmann R, et al. (2009) Structure-Based Optimization of Aldose Reductase Inhibitors Originating from Virtual Screening. ChemMedChem 4(5): 809-819.

15. Cosconati S, Marinelli L, La Motta C, Sartini S, Da Settimo F, et al. (2009) Pursuing Aldose Reductase Inhibitors through in Situ Cross-Docking and Similarity-Based Virtual Screening. Journal of Medicinal Chemistry 52(18): 5578-5581.

16. Vyas B, Singh M, Kaur M, Silakari O, Bahia MS, et al. (2016) Pharmacophore and docking-based hierarchical virtual screening for the designing of aldose reductase inhibitors: synthesis and biological evaluation. Medicinal Chemistry Research 25(4): 609-626.

17. Antony P, Vijayan R (2015) Identification of Novel Aldose Reductase Inhibitors from Spices: A Molecular Docking and Simulation Study. PLoS One 10(9): e0138186-e0138186.

18. Harrison DHT, Bohren KM, Petsko GA, Ringe D, Gabbay KH (1997) The Alrestatin Double-Decker: Binding of Two Inhibitor Molecules to Human Aldose Reductase Reveals a New Specificity Determinant. Biochemistry 36(51): 16134-16140.

19. Barski OA, Gabbay KH, Bohren KM (1996) The C-Terminal Loop of Aldehyde Reductase Determines the Substrate and Inhibitor Specificity. Biochemistry 35(45): 14276-14280.

20. Dixit BL, Balendiran GK, Watowich SJ, Srivastava S, Ramana KV, et al. (2000) Kinetic and Structural Characterization of the Glutathionebinding Site of Aldose Reductase. Journal of Biological Chemistry 275(28): 21587-21595.

21. Singh R, White MA, Ramana KV, Petrash JM, Watowich SJ, et al. (2006) Structure of a glutathione conjugate bound to the active site of aldose reductase. Proteins: Structure, Function, and Bioinformatics 64(1): 101-110.

22. Trott 0, Olson AJ (2010) AutoDock Vina: improving the speed and accuracy of docking with a new scoring function, efficient optimization, and multithreading. J Comput Chem 31(2): 455-461.

23. Dallakyan S, Olson AJ (2015) Small-Molecule Library Screening by Docking with PyRx. In: Hempel JE, Williams CH, Hong CC, (Eds.), Chemical Biology: Methods and Protocols Springer New York, USA, pp. 243-250.

24. Sarwar N, Gao P, Kondapally SSR, Gobin R, Kaptoge S (2010) Diabetes mellitus, fasting blood glucose concentration, and risk of vascular disease: a collaborative meta-analysis of 102 prospective studies. The Lancet 375(9733): 2215-2222.

25. Bourne RRA, Stevens GA, White RA, Smith JL, Flaxman SR, et al. (2013) Causes of vision loss worldwide, 1990-2010: a systematic analysis. The Lancet Global Health 1(6): e339-e349.

26. Saran R, Li Y, Robinson B, Ayanian J, Balkrishnan R, et al. (2015) Renal Data System 2014 Annual Data Report: Epidemiology of Kidney Disease in the United States. American Journal of Kidney Diseases 66 (Suppl 1), A7.

27. Yan LJ (2018) Redox imbalance stress in diabetes mellitus: Role of the polyol pathway. Animal Model Exp Med 1(1): 7-13.

28. Gabbay KH (2004) Aldose reductase inhibition in the treatment of diabetic neuropathy: Where are we in 2004? Current Diabetes Reports 4(6): 405-408.

29. Kurono M, Fujiwara I, Yoshida K (2001) Stereospecific Interaction of a Novel Spirosuccinimide Type Aldose Reductase Inhibitor, AS-3201, with Aldose Reductase. Biochemistry 40(28): 8216-8226.

30. Bril V, Hirose T, Tomioka S, Buchanan R (2009) Ranirestat for the Management of Diabetic Sensorimotor Polyneuropathy. Diabetes Care 32(7): 1256-1260. 
31. Ramunno A, Cosconati S, Sartini S, Maglio V, Angiuoli S, et al. (2012) Progresses in the pursuit of aldose reductase inhibitors: The structurebased lead optimization step. European Journal of Medicinal Chemistry 51: $216-226$.
32. Yasuo N, Watanabe K, Hara H, Rikimaru K, Sekijima M (2018) Predicting Strategies for Lead Optimization via Learning to Rank. IPS] Transactions on Bioinformatics 11: 41-47.

Your next submission with Juniper Publishers
will reach you the below assets
- Quality Editorial service
- Swift Peer Review
- Reprints availability
- E-prints Service
- Manuscript Podcast for convenient understanding
- Global attainment for your research
- Manuscript accessibility in different formats
( Pdf, E-pub, Full Text, Audio)
- Unceasing customer service
Track the below URL for one-step submission
https://juniperpublishers.com/online-submission.php

